\title{
Different LFP frequency bands convey complementary information about the BOLD signal
}

\author{
Cesare Magri ${ }^{1 *+}$, Ulrich Schridde ${ }^{1 \dagger}$, Stefano Panzeri ${ }^{3}$, Yusuke Murayama ${ }^{1}$, Nikos K Logothetis ${ }^{1,2}$ \\ From Twentieth Annual Computational Neuroscience Meeting: CNS*2011 \\ Stockholm, Sweden. 23-28 July 2011
}

Blood-oxygen-level-dependent (BOLD) functional magnetic resonance imaging (fMRI) is the most widely used noninvasive imaging technique for investigating brain activity. However, the BOLD signal is only indirectly coupled to the underlying neural activity and the relationship between the two signals is not fully understood [1]. Recordings in anaesthetized and awake monkeys have shown that hemodynamic responses are strongly related to local field potentials (LFPs) [2,3]. LFPs are thought to represent the input and intracortical processing in a cortical area and are usually separated into different frequency bands that reflect different neural processes [4]. Previous studies have shown that different LFP bands correlate differently with the BOLD signal $[3,5,6]$. However little is known about which property of the BOLD signal is reflected by each band and whether different bands convey different information about the BOLD signal. To address this question we performed simultaneous recordings of neural activity and BOLD fMRI in early visual areas V1 and V2 in 4 anesthetized monkeys. All measurements were performed with the monkeys sitting in complete darkness while no stimulus was being presented. We computed mutual information between LFP power and BOLD fMRI to determine which frequencies in the LFPs were most informative about the BOLD signal. We found three highly informative bands, namely the alpha band $[8-12 \mathrm{~Hz}]$, the gamma band [40$100 \mathrm{~Hz}]$ and the $[18-35 \mathrm{~Hz}]$ "nMod" band that was previously found to be unrelated to visual stimuli and was thus suggested to primarily reflect neuromodulatory

\footnotetext{
* Correspondence: cesare.magri@tuebingen.mpg.de

† Contributed equally

'Max Planck Institute for Biological Cybernetics, 38 Spemanstrasse, 72076

Tübingen, Germany

Full list of author information is available at the end of the article
}

input [4]. We found that gamma power was the most informative about BOLD fMRI and reflected well changes in the amplitude of the BOLD signal. In particular, an increase in gamma power above its median value was followed, on average, by an increase in BOLD signal, and the BOLD signal decreased, instead, following a decrease in gamma power below its median. Moreover, we found that gamma and nMod power were complementary, i.e. that by combining nMod power together with gamma power we could extract $30 \%$ more information than could be extracted from gamma power alone. We investigated the origin of this complementarity and we found that the power in the nMod band reflected the timing with which changes in BOLD signal occurred following changes in gamma power. Finally, we found that, as suggested by previous theoretical work [7], an increase in alpha power without a change in total LFP power was followed by a decrease in BOLD signal and vice versa. These results indicate that distinct neural processes are reflected differently in the BOLD signal and that, consequently, it may be possible to retrieve information about the different contributions from the recorded BOLD time course.

\section{Acknowledgments \\ * These authors contributed equally to the work.}

\section{Author details}

${ }^{1}$ Max Planck Institute for Biological Cybernetics, 38 Spemanstrasse, 72076 Tübingen, Germany. ${ }^{2}$ Imaging Science and Biomedical Engineering University of Manchester, Manchester, UK. ${ }^{3}$ Italian Institute of Technology, Department of Robotics, Brain and Cognitive Sciences, Genova, Italy.

Published: 18 July 2011 


\section{References}

1. Logothetis NK: What we can do and what we cannot do with fMRI. Nature 2008, 453(7197):869-878.

2. Logothetis NK, Pauls J, Augath M, Trinath T, Oeltermann A: Neurophysiological investigation of the basis of the fMRI signal. Nature 2001, 412(6843):150-157.

3. Goense JBM, Logothetis NK: Neurophysiology of the BOLD fMRI signal in awake monkeys. Curr Biol 2008, 18(9):631-640

4. Belitski A, Gretton A, Magri C, Murayama Y, Montemurro MA, Logothetis NK, Panzeri S: Low-frequency local field potentials and spikes in primary visual cortex convey independent visual information. J Neurosci 2008, 28(22):5696-5709.

5. Scholvinck ML, Maier A, Ye FQ, Duyn JH, Leopold DA: Neural basis of global resting-state fMRI activity. P Natl Acad Sci USA 2010, 107(22):10238-10243.

6. Scheeringa R, Fries P, Petersson KM, Oostenveld R, Grothe I, Norris DG Hagoort P, Bastiaansen MCM: Neuronal Dynamics Underlying High- and Low-Frequency EEG Oscillations Contribute Independently to the Human BOLD Signal. Neuron 2011, 69(3):572-583.

7. Kilner JM, Mattout J, Henson R, Friston $\mathrm{KJ}$ : Hemodynamic correlates of EEG: A heuristic. Neuroimage 2005, 28(1):280-286.

doi:10.1186/1471-2202-12-S1-P204

Cite this article as: Magri et al: Different LFP frequency bands convey complementary information about the BOLD signal. BMC Neuroscience 2011 12(Suppl 1):P204

\section{Submit your next manuscript to BioMed Central} and take full advantage of:

- Convenient online submission

- Thorough peer review

- No space constraints or color figure charges

- Immediate publication on acceptance

- Inclusion in PubMed, CAS, Scopus and Google Scholar

- Research which is freely available for redistribution

Submit your manuscript at www.biomedcentral.com/submit 